\title{
An observation campaign of precipitable water vapor with multiple GPS receivers in western Java, Indonesia
}

\author{
Eugenio Realini ${ }^{1,4^{*}}$, Kazutoshi Sato ${ }^{1,5}$, Toshitaka Tsuda1 ${ }^{1}$ Susilo ${ }^{2}$ and Timbul Manik ${ }^{3}$
}

\begin{abstract}
A campaign was conducted from 23 July to 5 August 2010 to measure atmospheric precipitable water vapor (PWV) using five Global Positioning System (GPS) receivers, stationed at four different locations in Jakarta and Bogor, western Java, Indonesia. Radiosondes were launched at an interval of $6 \mathrm{~h}$ to validate the GPS-derived PWV data. The validation resulted in a root mean square error of 2 to $3 \mathrm{~mm}$ in PWV. The influence of atmospheric pressure and temperature on GPS-derived PWV was evaluated. A regular semi-diurnal pressure oscillation was observed, showing an amplitude ranging from 3 to $5 \mathrm{hPa}$, which corresponds to 1.1 to $1.8 \mathrm{~mm}$ in PWV. A nocturnal temperature inversion layer was observed in the radiosonde profiles, which resulted in an error of about $0.5 \mathrm{~mm}$ in PWV. From 26 to 29 July, there was a passage of distributed rain clouds over western Java, moving southwestward from the equator toward the Indian Ocean. A second precipitation event, with scattered rain clouds forming locally near Bogor, occurred on 2 August. Both events were observed also by a C-band Doppler Radar operated near Jakarta. The highest peak of GPS-derived PWV (about $67 \mathrm{~mm}$ ) registered during the campaign occurred on 27 July, coinciding with the distributed rainfall event. Spatial variations in the estimated PWV between the four sites were enhanced before both the analyzed rainfall events, on 27 July and 2 August. Peaks in the temporal variability of PWV were also observed in conjunction with the two events. The results indicated a relation between the space-time inhomogeneity of GPS-PWV and rainfall events in the tropics.
\end{abstract}

Keywords: GPS; Radiosonde; PWV; Indonesia

\section{Background}

Accurate prediction of local heavy rainfall in Indonesia is difficult with current mesoscale numerical prediction models, partly because of the lack of a meteorological observation network. Global Navigation Satellite Systems (GNSS), which include the U.S. Global Positioning System (GPS), are widely used for civilian applications, including scientific studies and atmospheric monitoring. Bevis et al. (1992) initiated the interdisciplinary scientific field of GNSS meteorology, which derives the vertically integrated amount of water vapor in a column of atmosphere, i.e., the precipitable water vapor (PWV), from the analysis of tropospheric delays in GNSS signals.

\footnotetext{
*Correspondence: eugenio.realini@g-red.eu

1 Research Institute for Sustainable Humanosphere (RISH), Kyoto University, Gokasho, Uji 611-0011, Japan

4 Present address: Geomatics Research \& Development (GReD) srl, Como, Italy Full list of author information is available at the end of the article
}

The number of continuously operated GNSS stations has rapidly increased in Indonesia recently, up to the current 100 (IUGG 2011). These stations, operated by the Indonesian Geospatial Information Agency (Badan Informasi Geospatial (BIG)), provide the means for continuous monitoring of PWV in the Indonesian region and constitute a distributed GNSS observation network uniquely and usefully located in the tropical region. GPS-derived PWV measurements were earlier used for the study of the meteorological disturbances that occur in some areas of the tropics. For example, Wu et al. (2003) found a distinct diurnal variation in PWV from GPS measurements at a station located in Sumatra Island, Indonesia. PWV estimated by a GPS network installed along the west coast of Sumatra Island was also used to study diurnal variations in tropical convection in relation to the different Madden-Julian oscillation (MJO) phases (Fujita et al. 2011).

\section{Springer}

(c) 2014 Realini et al: licensee Springer. This is an Open Access article distributed under the terms of the Creative Commons Attribution License (http://creativecommons.org/licenses/by/4.0), which permits unrestricted use, distribution, and reproduction in any medium, provided the original work is properly credited. 
The GNSS meteorology technique consists in retrieving the amount of PWV in the column of air above a GNSS station antenna. The presence of atmospheric water vapor along the slant path from each satellite to the station antenna causes a delay in the signal propagation: these delays are used to estimate the delay in the vertical direction (zenith total delay (ZTD)). The ZTD is then separated into its hydrostatic ('dry') and non-hydrostatic ('wet') components, respectively called zenith hydrostatic delay (ZHD) and zenith wet delay (ZWD). Details about this procedure are given in the section 'PWV retrieval method'. The ZWD is converted to PWV by means of the weighted mean temperature of the atmosphere $\left(T_{\mathrm{m}}\right)$, which can be calculated from the profiles of temperature and partial pressure of water vapor. However, a simplified relation between the measured surface temperature $\left(T_{\mathrm{s}}\right)$ and $T_{\mathrm{m}}$ is often employed, since these profiles are not always available. Bevis et al. (1992) performed a regression analysis between $T_{\mathrm{s}}$ and $T_{\mathrm{m}}$ using radiosonde data collected in North America. Wang et al. (2005) compared and analyzed global estimates of $T_{\mathrm{m}}$ from three different data sets from the year 1997 to 2002 . They found that by following the Bevis model, problems in estimating the value of $T_{\mathrm{m}}$ arise because of the erroneously large diurnal atmospheric temperature cycle it produces, owing to the diurnally invariant $T_{\mathrm{s}}-T_{\mathrm{m}}$ relationship and large diurnal variation in surface temperature. They also evidenced a cold bias of $T_{\mathrm{m}}$ derived from the Bevis model in the tropics and subtropics and a warm bias in the middle and high latitudes.

The present study aims to investigate the applicability of the GPS meteorology technique for estimating PWV in and around Jakarta, Indonesia. To this aim, we examined whether the $T_{\mathrm{s}}-T_{\mathrm{m}}$ relation holds true in the case of the Indonesian tropical environment. We should stress here that the main purposes of this study are to analyze the horizontal inhomogeneity of PWV with multiple GPS receivers and to identify its relation to tropical convective rain events. Earlier studies, although not using GPS, analyzed the effects of the trans-equatorial flow and the $\mathrm{MJO}$ on torrential rains, respectively on Java Island (Wu et al. 2007) and on western Java Island (Wu et al. 2013). However, to our knowledge, the study presented here is the first attempt to quantitatively investigate the relation between space-time variations of GPS-derived PWV and severe rain events over western Java.

We conducted an observation campaign to monitor the PWV around Jakarta for a period of over 10 days during July to August 2010. A total of 21 radiosondes were launched, and GPS observations from four different sites, located in the west part of the Java Island, were analyzed. During this campaign, active storm clouds passed over the GPS sites, and the consequent time variations in the GPS-derived PWV values were successfully measured. An effort was made to discuss a possible relationship between the time variations in GPS-derived PWV and the rainfall events.

\section{Methods}

\section{Experimental setup}

The GPS experiment was carried out from 23 July to 5 August 2010, in collaboration with the Indonesian Geospatial Information Agency (BIG), the National Institute of Aeronautics and Space (LAPAN), and the Bandung Institute of Technology (ITB). Figure 1 shows the location of the GPS receiver sites, the radiosonde launch site, the routine weather station that was used in this work, and the location of the C-band Doppler Radar (CDR) that was used to evaluate the distribution of rain clouds over the area of interest. This CDR is installed in Serpong (Yamanaka et al. 2008) and, during the campaign described in this paper, was operated by the Japan Agency for Marine-Earth Science and Technology (JAMSTEC) in collaboration with the Indonesian Agency for the Assessment and Application of Technology (BPPT). In addition to the continuously operated GPS stations of BIG, indicated as CJKT (Jakarta) and CTGR (Tangerang) in Figure 1, we installed two more receivers, one at the LAPAN observatory in Pekayon (PKYN) and one close to the IGS (International GNSS Service) station of BAKO, named BAK2. Note that these last two GPS stations (i.e., BAKO and BAK2) were operated at about $80 \mathrm{~m}$ of distance one from the other, within the main office

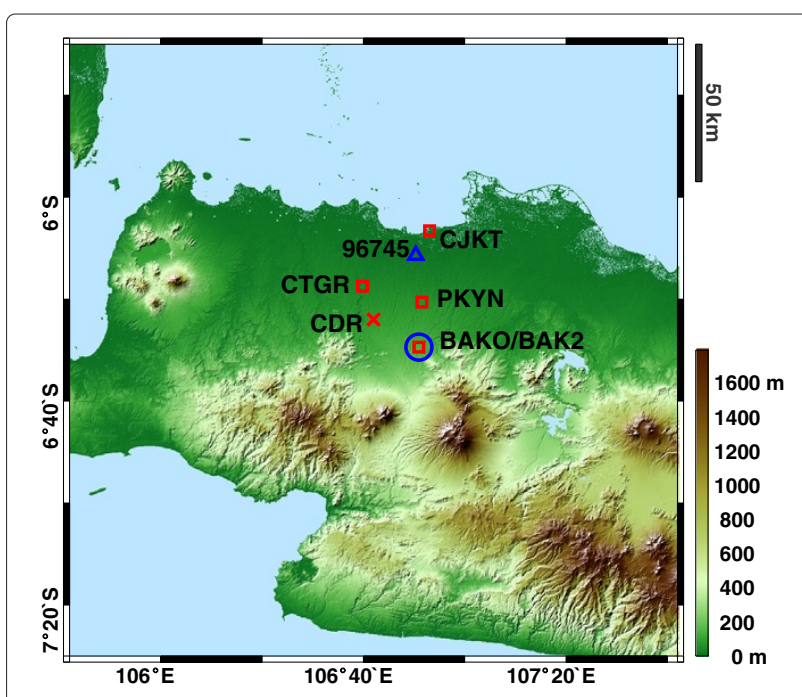

Figure 1 Experimental setup. Spatial distribution of the GPS stations (squares), with marker names CJKT (Jakarta), CTGR (Tangerang), PKYN (Pekayon), BAKO and BAK2 (Bakosurtanal); the BMKG weather monitoring station (triangle), identified by its WMO code; the radiosonde launch site (circle); the C-band Doppler Radar (CDR) at Serpong (cross). 
campus of BIG. The extent of the experimental domain was about $40 \mathrm{~km}$ (north-south) $\times 25 \mathrm{~km}$ (east-west). BAKO station was chosen as a reference for the comparison described in the section 'Comparison between GPS - and radiosonde-derived PWV' both because of its proximity to the radiosonde launch site (about $100 \mathrm{~m}$ ) and because it is an official IGS station, therefore subject to routine checks and validation. Observations from all the GPS stations were sampled at $1 \mathrm{~s}$ interval. All the GPS sites were located to the north of a mountainous region of Java Island, facing the ocean. The topography shows a gradually decreasing altitude from south to north, with the largest height difference among stations being about $130 \mathrm{~m}$, between BAKO and CJKT. Twenty-one radiosondes (Vaisala RS92-SGPD) were launched from the BIG campus (near BAKO and BAK2 stations), with a time interval of $6 \mathrm{~h}$, at 0030, 0630, 1230 (at times postponed to 1630), and 1830 local time (LT), to obtain detailed vertical profiles up to about $30 \mathrm{~km}$ altitude. The average vertical resolution of radiosonde observations was about 10 $\mathrm{m}$. Surface pressure and temperature were continuously monitored only at CTGR, using a Vaisala PTU-300, with a rate of $30 \mathrm{~s}$. Hence, we have also referred to the 3-hourly meteorological records collected by the weather stations of the Meteorological, Climatological and Geophysical Agency of Indonesia (BMKG). Atmospheric surface pressure was also measured at the radiosonde launch point, by means of a calibrated aneroid pressure gauge, used for the ground-check of the radiosonde pressure sensor. Pressure and temperature observations from the BAKO station weather sensor were also made available starting from 2 August.

The GPS observations were processed by using RTNet ver.3.3.0 (Rocken et al. 2001), which estimates the ZTD as a Kalman filter parameter by the precise point positioning (PPP) method (Zumberge et al. 1997). The satellite orbits and clock offsets used for the processing are those provided in the IGS final products. Other settings include a processing rate of $30 \mathrm{~s}$, satellite elevation cutoff of $10^{\circ}$, the dry and wet formulations of the Global Mapping Function (Böhm et al. 2006) for mapping slant delays to the zenith direction, and the GOT4.8 model (Ray 2013) to account for the ocean loading. RTNet was earlier applied for retrieving PWV (or more precisely, for estimating the ZTD that was then converted to PWV), and the results were compared with radiosondes and radiometers (Fujita et al. 2008, Sato et al. 2013), yielding a root mean square error (RMSE) of about $2 \mathrm{~mm}$.

It should be noted that the IGS final products are generally available with a latency of 2 to 3 weeks; therefore, they can be used only for non-real-time analyses like those described in this paper. Setting up a nowcasting system based on GPS/GNSS would require using near real-time satellite orbits and clocks, which are generally less accurate. However, it must be taken into account that the geodetic community is already tackling the problem of providing near real-time products with higher accuracy, as for example by the IGS Real-Time Service (RTS) (IGS 2012), which is currently being tested also for water vapor retrieval (Li et al. 2014).

\section{PWV retrieval method}

The ZHD for each GPS station was calculated by using the Saastamoinen model (Saastamoinen 1973), as

$$
\mathrm{ZHD}=0.0022768 P(1+0.00266 \cos 2 \phi+0.00028 H)
$$

where $P$ is the surface pressure, $\phi$ is the latitude of the GPS station antenna, and $H$ is its orthometric height in kilometers. The ground pressure at each station was retrieved as explained in the section 'Pressure analysis and adjustment'. The EGM2008 geoid model (Pavlis et al. 2012) was interpolated at each station location for converting the ellipsoidal height to orthometric height. The zenith wet delay (ZWD) was obtained by subtracting the ZHD from the ZTD, and the amount of precipitable water vapor was then retrieved from the wet delay as

$$
\mathrm{PWV}=Q \cdot \mathrm{ZWD}
$$

The conversion coefficient $Q$ is a function of the weighted mean temperature of the atmosphere $T_{\mathrm{m}}$, which can be computed on the basis of radiosonde observations (details are provided in the section 'Regression relation between $T_{\mathrm{s}}$ and $T_{\mathrm{m}}$ '); however, since radiosonde launch sites sufficiently close to GPS stations are often not available, $T_{\mathrm{m}}$ is generally modeled as a function of the surface temperature $T_{\mathrm{s}}$, as described in the next subsection. $Q$ is calculated by the formula proposed by Askne and Nordius (1987):

$$
Q=\frac{10^{8}}{\rho R_{\mathrm{W}}\left(\left(k_{3} / T_{\mathrm{m}}\right)+k_{2}^{\prime}\right)}
$$

where $\rho$ is the density of liquid water $\left(1,000 \mathrm{~kg} \mathrm{~m}^{-3}\right), R_{\mathrm{w}}$ is the specific gas constant of water vapor $\left(461.5 \mathrm{~J} \mathrm{~kg}^{-1}\right.$ $\left.\mathrm{K}^{-1}\right), T_{\mathrm{m}}$ is a modeled weighted mean temperature of the atmosphere (in K) and $k_{2}^{\prime}=k_{2}-m k_{1}$, where $m$ is the ratio of molar masses of water vapor and dry air $\left(M_{\mathrm{w}} / M_{\mathrm{d}}=\right.$ $0.622)$. The atmospheric refractivity constants $k_{1}, k_{2}$, and $k_{3}$ used in this work are those proposed by Bevis et al. (1994), yielding $k_{2}^{\prime}=22.1 \mathrm{~K} \mathrm{mbar}^{-1}$ and $k_{3}=3.73910^{5}$ $\mathrm{K}^{2}$ mbar $^{-1}$.

The amount of PWV was estimated from radiosonde observations by integrating the water vapor density between the ground altitude $\left(h_{1}\right)$ and the altitude at which 
each radiosonde measured the $99 \%$ of the total accumulated water vapor ( $h_{2}$, ranging from 7 to $\left.9 \mathrm{~km}\right)$, discretized according to the radiosonde altitude steps, i.e.,

$$
\mathrm{PWV}=\int_{h_{1}}^{h_{2}} \rho_{\mathrm{w}} \mathrm{d} h=\sum_{i=1}^{n} \rho_{\mathrm{d}, i} r_{i} \Delta h_{i}
$$

where $\rho_{\mathrm{w}}$ is the water vapor density, $n$ is the total number of layers between $h_{1}$ and $h_{2}$, and $\rho_{\mathrm{d}, i}, r_{i}, \Delta h_{i}$ are respectively the dry air density, the mixing ratio, and the altitude step for layer $i$. Dropping the index $i$ for the sake of simplicity, the dry air density $\rho_{\mathrm{d}}$ is expressed as

$$
\rho_{\mathrm{d}}=\frac{M_{\mathrm{d}}}{R} \frac{P}{T}
$$

with the molar mass of dry air $M_{\mathrm{d}}=0.0289644 \mathrm{~kg} \mathrm{~mol}^{-1}$ and the universal gas constant for air $R=8.31432 \mathrm{~J} \mathrm{~mol}^{-1}$ $\mathrm{K}^{-1} . T$ is the observed air temperature in Kelvin. The mixing ratio $r$ is defined as the dimensionless ratio of the mass of water vapor to the mass of dry air. Based on the ideal gas law, the following relations can be derived:

$$
r=0.622 \frac{e}{P-e} \approx 0.622 \frac{e}{P}
$$

where $e$ is the partial pressure of water vapor and $P$ is the air pressure. The product between Equations 6 and 5 required to apply Equation 4 thus yields a quantity independent of $P$.

The partial pressure of water vapor $e$ is computed from radiosonde observations as follows:

$$
e=\frac{U}{100} e_{\mathrm{s}}
$$

where $U$ is the observed relative humidity and $e_{\mathrm{s}}$ is the saturation vapor pressure, calculated by the following equation (WMO 2008):

$$
e_{\mathrm{s}}=6.112 \exp \left(\frac{17.62 T}{243.12+T}\right)
$$

with $T$ the observed temperature in degrees Celsius.

\section{Regression relation between $T_{s}$ and $T_{m}$}

Since water vapor is mostly concentrated in the lower atmosphere, $T_{\mathrm{m}}$ is expected to be closely correlated to the surface temperature $T_{\mathrm{s}}$. Bevis et al. (1992) derived the following equation from radiosonde observations over 2 years, under various conditions, taken from $27^{\circ} \mathrm{N}$ to $65^{\circ}$ $\mathrm{N}$ from 13 stations in North America, from 0 to $1.6 \mathrm{~km}$ of altitude

$$
T_{\mathrm{m}}=70.2+0.72 T_{\mathrm{s}}
$$

Shoji (2010) also derived a similar relation using radiosonde observations collected during 1 year from 20 stations in Japan, which was reported to be more appropriate for the Japanese regional meteorological conditions. Equations 10 and 11 were derived at 0900 and 2100 LT, respectively, to separately represent day and night conditions

$$
\begin{aligned}
& T_{\mathrm{m}}=27.008+0.8688 T_{\mathrm{s}} \\
& T_{\mathrm{m}}=20.072+0.8956 T_{\mathrm{s}} .
\end{aligned}
$$

After comparing our experimental results from radiosondes with the models described in Equations 9 to 11 (see the next two paragraphs), we decided to employ Equation 10 as a reasonable approximation for both our daytime and nighttime results.

Figure 2 shows the temperature profiles obtained in our radiosonde experiments. It is evident that a temperature inversion layer appeared near the ground at night (launches at $0030 \mathrm{LT}$ ) and early morning (launches at 0630 LT) every day. The observed relation between $T_{\mathrm{s}}$ and $T_{\mathrm{m}}$ during this campaign was evaluated in order to check which of the existing $T_{\mathrm{s}}-T_{\mathrm{m}}$ models was more suitable to be applied in our experiment. For each radiosonde launch, the weighted mean temperature of the atmosphere $T_{\mathrm{m}}$ was computed as (Bevis et al. 1992; Davis et al. 1985)

$$
T_{\mathrm{m}}=\frac{\int e / T \mathrm{~d} h}{\int e / T^{2} \mathrm{~d} h}
$$

where $e$ is the partial pressure of water vapor (computed from the radiosonde humidity and temperature readings, see Equation 7) and $T$ is the radiosonde temperature reading. The integration was performed from the ground level up to the maximum altitude reached by the radiosonde (it is worth pointing out that, in this equation, the partial pressure of water vapor $e$ acts as a weight for the temperature observations, which will therefore have a decreasing influence on the result as the altitude increases).

Figure 3 shows scatter diagrams between $T_{\mathrm{s}}$ and $T_{\mathrm{m}}$ obtained from the radiosonde observations collected in this campaign; on the left, the results when considering the full temperature profiles, while on the right by assuming ground level at $300 \mathrm{~m}$ height, in order to remove the effect of the inversion layer. The daytime results show a reasonable agreement with the Bevis model (Equation 9) in both cases. However, the nighttime results indicate a considerable bias from the Bevis model, showing a positive deviation of 2 to $4 \mathrm{~K}$. While the agreement improves when removing the inversion layer, a significant bias is still present. $T_{\mathrm{m}}$, therefore, tends to be overestimated by the Bevis model at night due to the inversion layer that occurs near the ground. The nighttime results tend to 


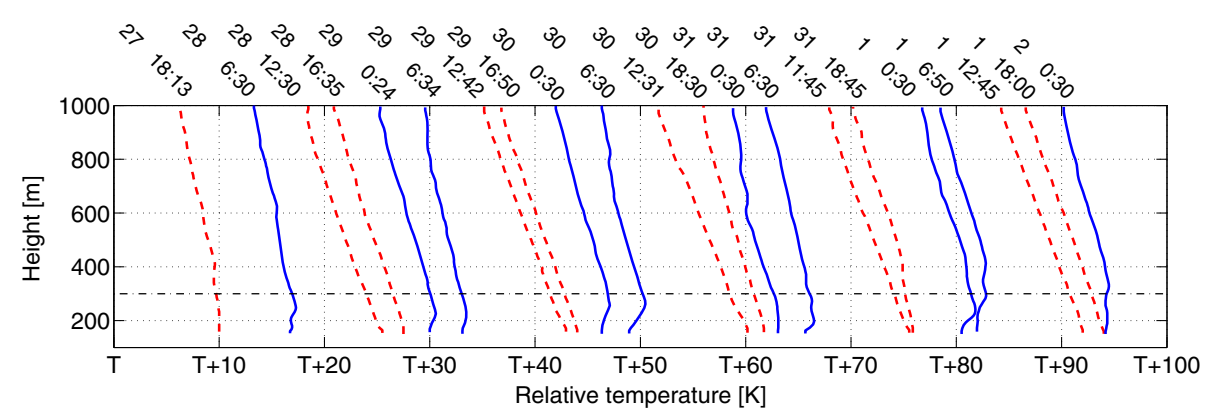

Figure 2 Radiosonde temperature profiles. Temperature profiles observed during daytime (dashed red line) and nighttime (solid blue line) radiosonde launches. Profile plots are shifted along the $x$-axis, in order to improve the figure readability; therefore, the $x$-axis only shows temperature increments of $10 \mathrm{~K}$. The horizontal dash-dotted line indicates the minimum height threshold (300 m) used to exclude the inversion layer for the regression analysis.

agree better with the Shoji nighttime model (Equation 11) compared to the Bevis model, in both cases. However, the daytime results show a negative bias with respect to the Shoji daytime model (Equation 10). The effects of the $T_{\mathrm{m}}$ deviation on the GPS-PWV estimates were investigated. If the model $T_{\mathrm{m}}$ introduces a $3 \mathrm{~K}$ error with respect to the actual weighted average temperature, the corresponding error in PWV is about $0.5 \mathrm{~mm}$. It is worthwhile noting that even if a mismodeling of this order of magnitude is introduced, it would not have a significant impact on the results described in this paper: in fact, as described later on in the section 'Spatial variations of GPS-derived PWV around Jakarta', the expected GPS-derived PWV error standard deviation in this campaign is about $1 \mathrm{~mm}$, while the observed horizontal PWV fluctuations have a standard deviation ranging from 1 to $4 \mathrm{~mm}$. It should also be pointed out that, in the particular case of this campaign, the choice between the three previously described models is not critical: since all stations would be similarly affected, the impact on the inter-station PWV differences would be very limited. Therefore, we decided to use the Shoji daytime model for the whole campaign, as it is a reasonable compromise to approximate both daytime and nighttime results.

In general, it is difficult to reach a firm conclusion on the resulting regression relations in our campaign, as the number of available radiosonde observations is too small. An appropriate relationship between $T_{\mathrm{s}}$ and $T_{\mathrm{m}}$ for the Indonesian area should be constructed, also by considering regional weather conditions, such as the inversion layer occurrence. To reach this goal, one could investigate more radiosonde profiles from routine soundings over Indonesia, e.g., by accessing radiosonde observations by BMKG, which are available through the Global Telecommunications Service (GTS) datasets. However, since the observable temperature ranges in the tropics are generally
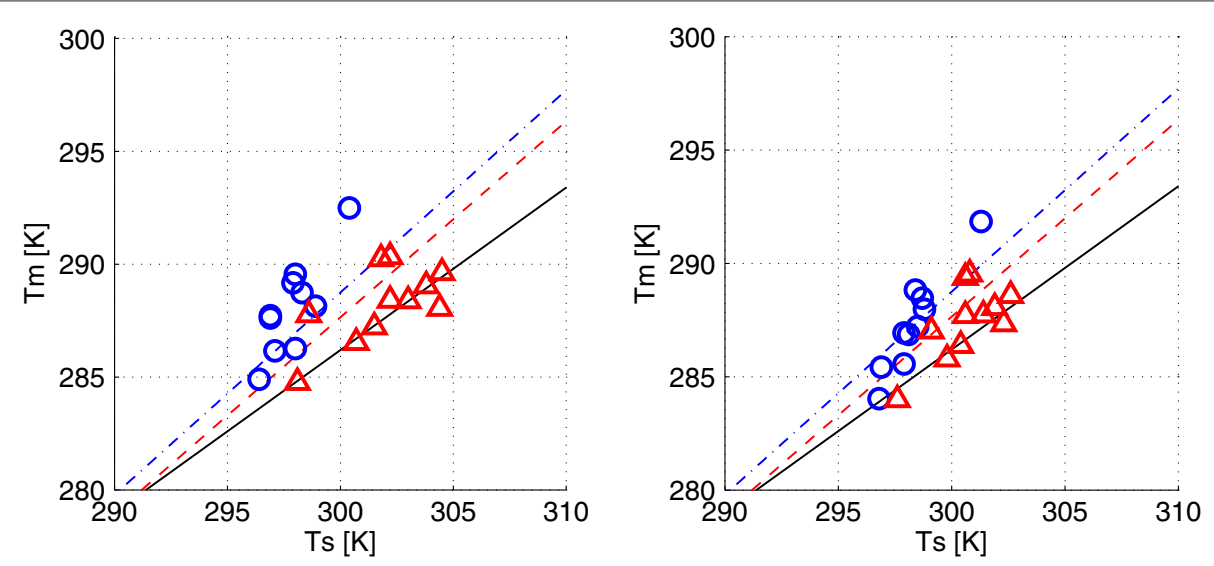

Figure 3 Scatter diagrams of $\boldsymbol{T}_{\mathrm{s}}$ and $\boldsymbol{T}_{\mathrm{m}}$. Relationship between the surface temperature $T_{\mathrm{s}}$ and the weighted mean temperature of the atmosphere $T_{\mathrm{m}}$. On the left, by using profiles above the ground level; on the right, by using profiles above $300 \mathrm{~m}$ of height (red triangles, daytime observations; blue circles, nighttime observations; black solid line, Bevis model; red dashed line, Shoji daytime model; blue dash-dotted line, Shoji nighttime model). 
limited to about $10 \mathrm{~K}$, it is difficult to carry out a reliable regression analysis as it was done for Bevis and Shoji models.

\section{Pressure analysis and adjustment}

Observations from five GPS receivers were used during this experiment, with marker names CJKT (orthometric height $13 \mathrm{~m}$ ), CTGR (48 m), PKYN (69 m), BAKO $(141 \mathrm{~m})$, and BAK2 $(150 \mathrm{~m})$; the last two receivers were located closely within the campus of BIG. However, surface pressure was measured continuously at CTGR only. As pressure data is very important in estimating GPSderived PWV, to separate the hydrostatic and wet components of the signal delay, we investigated the accuracy of the pressure measurements at CTGR and the feasibility of adjusting CTGR pressure measurements to different heights in order to have sufficiently accurate pressure measurements for each GPS station. The original surface pressure measured at CTGR ( $P_{\mathrm{CTGR}}$, black solid line in Figure 4) was converted to the pressure at the height of station 96745 ( $P_{96745}$, orthometric height $\left.8 \mathrm{~m}\right)$ by using the following relationship, derived from the barometric formula in Berberan-Santos et al. (1997)

$$
P_{96745}=P_{\mathrm{CTGR}} \exp \left(-\frac{g M_{\mathrm{d}}\left(H_{96745}-H_{\mathrm{CTGR}}\right)}{R^{*} T_{\mathrm{ISA}}}\right)
$$

where $g$ is the gravitational acceleration constant $(9.80665$ $\left.\mathrm{m} \mathrm{s}^{-2}\right), M_{\mathrm{d}}$ is the molar mass of dry air $(0.0289644 \mathrm{~kg}$ $\left.\mathrm{mol}^{-1}\right), R^{*}$ is the gas constant for air $\left(8.31432 \mathrm{~J} \mathrm{~mol}^{-1}\right.$ $\mathrm{K}^{-1}$ ), and $T_{\mathrm{ISA}}$ is the international standard temperature of the atmosphere at sea level $(288.15 \mathrm{~K})$. $H_{\mathrm{CTGR}}$ and $H_{96745}$ are the orthometric heigths of CTGR and 96745 stations, respectively. Figure 4 shows the computed pressure $P_{96745}$ time series as a dashed line, while the weather station measurements are represented by white circles. Their agreement is very good, with a bias (computedmeasured) of $-0.03 \mathrm{hPa}$ and a standard deviation of 0.55 hPa. Next, we applied Equation 13 to compare the heightcorrected CTGR pressure data with the aneroid barometer readings (orthometric height $141 \mathrm{~m}$, black circles in Figure 4), obtaining a bias of $-0.72 \mathrm{hPa}$ and a standard deviation of $1.24 \mathrm{hPa}$. The larger random error is likely due to the lower precision of the aneroid barometer and to possible human error in reading the result. Lastly, the comparison with the observations of the weather sensor of BAKO station (dark grey line in Figure 4) yielded a bias of $-0.19 \mathrm{hPa}$ and a standard deviation of $0.23 \mathrm{hPa}$. Given that a pressure error of $1 \mathrm{hPa}$ roughly corresponds to $0.4 \mathrm{~mm}$ of error in PWV, we assume that the heightcompensated pressure data at CTGR can be used for PWV estimation. This dataset is thus used to infer the pressure values at CJKT, PKYN, and BAKO/BAK2 stations.

It is well known that a 12-h oscillation in the pressure is evident at low latitudes because of atmospheric tides

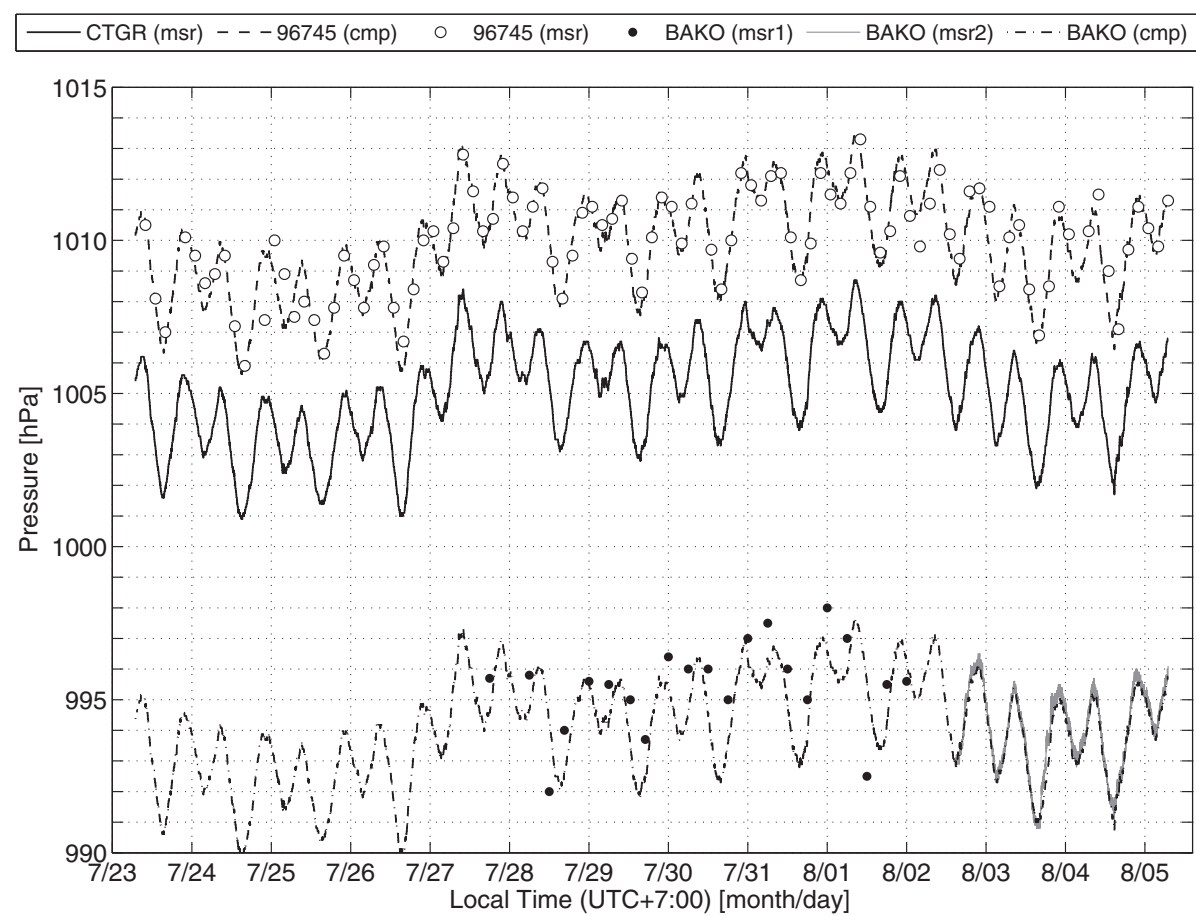

Figure 4 Pressure comparison. Measured (msr) and computed (cmp) pressure time series. 
(Covey et al. 2011; Lindzen and Chapman 1969). The magnitude and local time of the maximum value for the semidiurnal variations in Figure 4 are generally consistent with results reported in the literature. It is important to note that the influence of the observed semi-diurnal pressure variations ( 3 to $5 \mathrm{hPa}$ ) on the estimated PWV is about 1.1 to $1.8 \mathrm{~mm}$; therefore, at low latitudes, it is important to consider the effects of semi-diurnal tides for GPS-derived PWV retrieval. Pressure measurements with a time resolution higher than $1 \mathrm{~h}$ is recommended. The effects of space-time variations of pressure and temperature may not be significant to estimate GPS-derived PWV for meteorological phenomena with horizontal scales larger than several tens of kilometers, with relatively small horizontal gradients in pressure and temperature, as it is the case for this work. However, if a precise local-scale spatial distribution of PWV is investigated by means of a denser GPS network, it becomes important to accurately retrieve the PWV by referring to the simultaneous measurements of pressure and temperature at each GPS site.

\section{Temperature adjustment}

While pressure can be adjusted with good accuracy on the basis of the altitude difference between two stations, the surface temperature is generally more variable spatially; thus, it cannot be reliably inferred from one station to another. In this work, the only correction applied to CTGR surface temperature in order to use it with the other stations is the following height adjustment (Bai and Feng 2003):

$$
T_{\text {station }}=T_{\text {CTGR }}+0.0065 \times\left(H_{\text {CTGR }}-H_{\text {station }}\right)
$$

where $T_{\mathrm{CTGR}}$ and $T_{\text {station }}$ are respectively the temperature measured at CTGR and that inferred at the other station, and $H_{\text {CTGR }}$ and $H_{\text {station }}$ are the orthometric heights of the two stations. However, in the specific case of the campaign described in this paper, this adjustment is hardly significant, being at most $0.9 \mathrm{~K}$ when considering the maximum altitude difference between stations, that is between CJKT $(13 \mathrm{~m})$ and BAK2 $(150 \mathrm{~m})$, which corresponds to about $0.16 \mathrm{~mm}$ in PWV.

\section{Results and discussion}

\section{Comparison between GPS- and radiosonde-derived PWV}

Figure 5 shows the 21 radiosonde-derived PWV values and the time series of GPS-derived PWV using BAKO station. The GPS-derived PWV for the comparison was computed both by using the ground temperature measured at CTGR station, after having applied the height correction shown in Equation 14 (line in Figure 5), and by using the temperature readings of the radiosonde sensor at launch (circles in Figure 5). Each radiosonde PWV value was compared to the averaged GPS PWV values over a time span of 30 minutes from the radiosonde launch, in order to take into account the radiosonde measurement time. Two significantly larger values (i.e., exceeding twice the standard deviation of the differences) were identified at 1845 LT on 31 July and 0030 LT on 1 August. A possible explanation for these two anomalies could be the presence of strong disturbances localized in proximity of BAKO station, causing strong spatial and time variation of water vapor: sharp increments in the PWV time series of BAKO are evident in Figure 5, and increased PWV variability in both time and space for the whole network was observed (see Figure 6). The comparison results are shown in Table 1, which reports mean, standard deviation and RMSE of the PWV difference between radiosonde and GPS, either by using the temperature measured at CTGR ( $\left.T_{\mathrm{CTGR}}\right)$ or that measured by the radiosonde sensor at launch ( $\left.T_{\text {sonde }}\right)$, including and

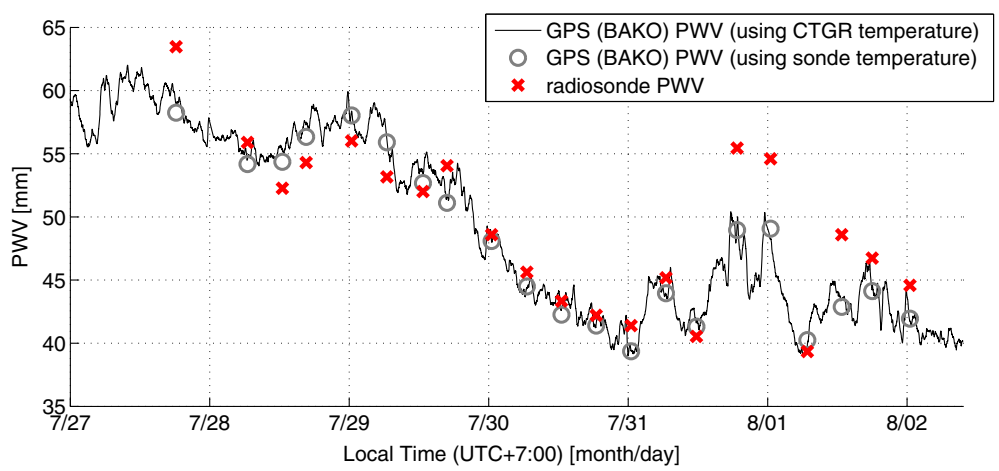

Figure 5 Radiosonde-GPS comparison. Comparison between the PWV retrieved from radiosondes (crosses) and by the GPS station BAKO. The GPS-derived PWV was computed by using the temperature measured at CTGR station (line) and that measured by the radiosonde sensor at launch (circles). 


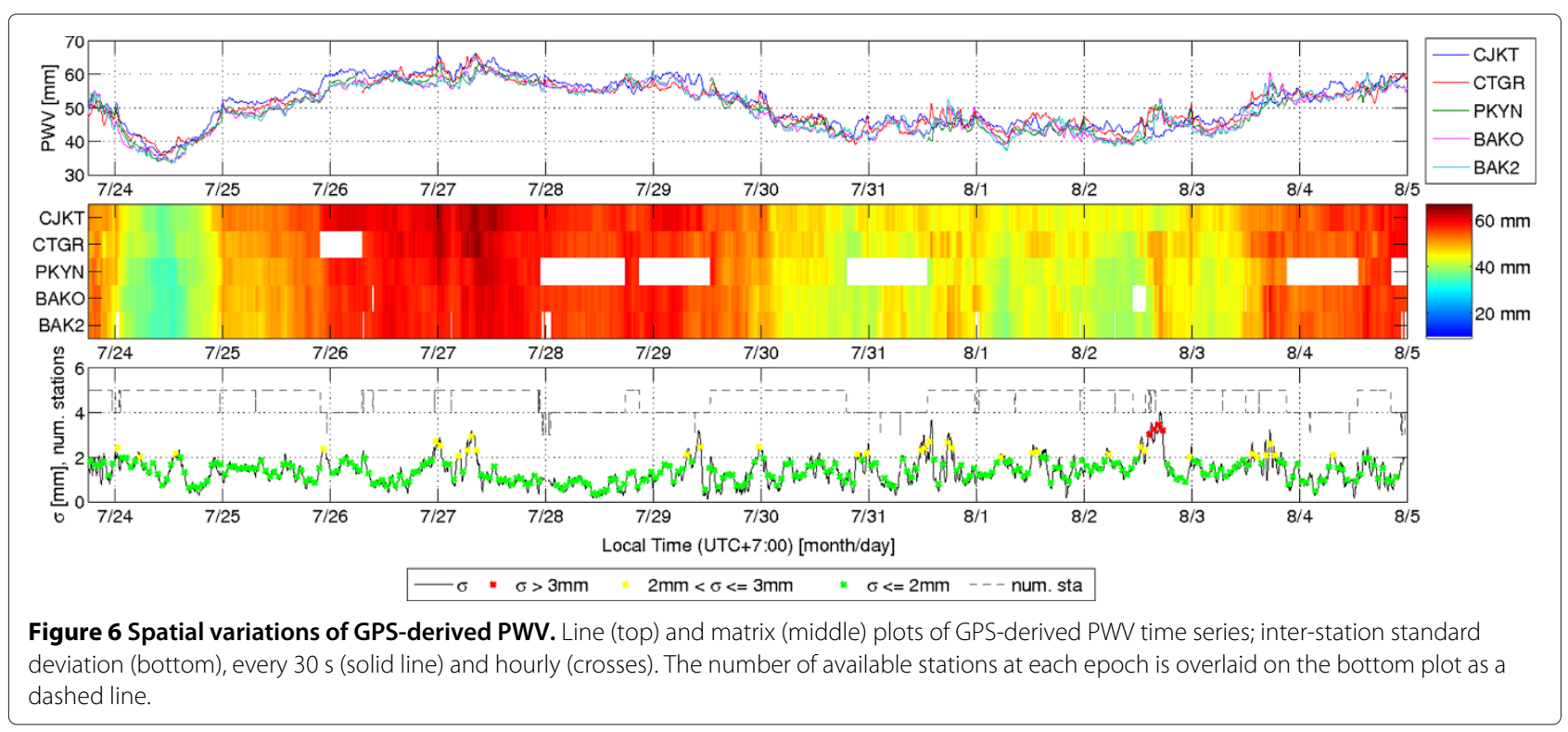

excluding the two anomalous values. The magnitude of the deviation is consistent with that reported in previous studies (Fujita et al. 2008; Sato et al. 2013). As regards the bias, previous comparisons of GPS-derived PWV with respect to Vaisala radiosondes, both in mid-latitude (by using the RS80H model (Deblonde et al. (2005) and the RS90 model (Van Baelen et al. 2005)) and tropical zones (RS80-15G model (Sapucci et al. 2007), RS80A, RS80H, and RS90 models (Wang et al. 2007), and RS92 model (Yoneyama et al. 2008)), evidenced a negative (dry) bias of the radiosonde measurements. This systematic error, especially significant during daytime, is generally attributed to the solar heating of the radiosonde humidity sensor (Vömel et al. 2007). However, examples exist in the literature that report also positive (moist) biases of Vaisala radiosonde measurements with respect to GPS. For example, Fernández et al. (2010) reported both moist and dry biases of Vaisala RS80 radiosonde observations compared to GPS in Argentina, varying according to different radiosonde launch sites and different models used for estimating the weighted mean temperature of the

Table 1 Mean, standard deviation, and RMSE of the difference between radiosonde and GPS results for PWV retrieval (in $\mathrm{mm}$ )

\begin{tabular}{lcccc}
\hline & $\boldsymbol{T}_{\text {CTGR }}$ & $\boldsymbol{T}_{\text {sonde }}$ & $\begin{array}{c}\boldsymbol{T}_{\text {CTGR }} \\
\text { (excluding anomalies) }\end{array}$ \\
\hline Mean & 1.1 & 1.3 & 0.5 & 0.7 \\
St.dev. & 3.0 & 3.0 & 2.4 & 2.3 \\
RMSE & 3.2 & 3.3 & 2.4 & 2.4 \\
\hline
\end{tabular}

st.dev., standard deviation. atmosphere $T_{\mathrm{m}}$. The European network of GPS stations (EUREF Permanent Network (EPN)) routinely compares GPS - and radiosonde-derived zenith tropospheric delays and publishes up-to-date time series on its website (EPN 2001): several of the published time series of radiosondeGPS differences exhibit moist biases ${ }^{\text {a }}$, generally of less than $1 \mathrm{~mm}$ (PWV) in magnitude. It must be noted that these examples of moist biases were reported in midlatitudes. Wang and Zhang (2008) demonstrated that the subsequent improvements to Vaisala radiosonde models from the RS80A to the RS92 have significantly mitigated the impact of the dry bias with respect to GPS-derived PWV, particularly for PWV values ranging from 40 to $60 \mathrm{~mm}$. However, it should also be pointed out that the timespan of our observation campaign is quite limited compared to those that would be needed to reliably quantify the difference between GPS-derived and radiosondemeasured PWV from a statistical point of view; more extensive radiosonde and GPS observation campaigns would be needed in order to quantify the nature of the bias (if any) in this region.

\section{Spatial variations of GPS-derived PWV around Jakarta}

Figure 6 shows the time series of GPS-derived PWV during the whole campaign (top and middle panels); all the five stations showed consistent time variations over long timespans (i.e., they showed consistent low-frequency signals) with maximum spatial variations (i.e., inter-station PWV differences) ranging from 5 to $10 \mathrm{~mm}$. The matrix representation in the middle panel was chosen in order to try to identify the movement of large water vapor fluctuations as they are detected by different stations; the stations are ordered from the northernmost (top row, CJKT) to 
the southernmost (bottom row, BAK2) to improve the readability of the plot. The PWV showed a local minimum around midday on 24 July, after which it started to increase rapidly in the late afternoon and continued to increase until the early morning of the 27 of July, with some intermittent fluctuations, reaching a peak of about $67 \mathrm{~mm}$. Then it gradually decreased on 29 to $30 \mathrm{July}$, stabilizing within a range of 40 to $50 \mathrm{~mm}$ until 3 August, when it started to increase again. Overall, Figure 6 indicates that a moist air block passed over the campaign site, causing the detection of a large amount of water vapor on 26 to 29 July. It is also worth noting that from 31 July to 3 August a diurnal variation in PWV is regularly repeated, with an enhancement in the afternoon (further details are given in the section 'Temporal variations of GPS-derived PWV around Jakarta').

The measurement error in PWV retrieval by GPS was roughly evaluated by comparing the PWV time series of the two co-located stations, i.e., BAKO and BAK2: the mean and standard deviation of their difference were 0.02

Table 2 Precipitation events detected by the CDR during the campaign

\begin{tabular}{|c|c|c|c|c|c|}
\hline Date & Time (LT) & Event & $\begin{array}{l}\text { max. reflectivity } \\
\text { (dBZ) }\end{array}$ & $\begin{array}{l}\text { max. st.dev. } \\
(\mathrm{mm})\end{array}$ & Notes \\
\hline 24 July & 1332 to 1922 & No data & - & 2.3 & \\
\hline 25 July & 1120 to 2200 & Scattered weak echoes & 20 & 2.1 & \\
\hline 25 July & 2200 to 2359 & Localized echoes & 30 & 2.4 & $\begin{array}{l}\text { Echoes approaching the observation area from } \\
\text { northeast }\end{array}$ \\
\hline 26 July & 0000 to 0200 & Localized echoes over CJKT & 30 & 1.5 & CJKT PWV higher than other stations \\
\hline 26 July & 0300 to 0700 & Scattered echoes & 30 & 2.1 & Echoes homogeneously covering the observation area \\
\hline 26 July & 2330 to 2359 & Scattered strong echoes & 50 & 2.6 & $\begin{array}{l}\text { Echoes approaching the observation area from } \\
\text { northeast }\end{array}$ \\
\hline 27 July & 0000 to 2359 & Scattered strong echoes & 60 & 3.1 & $\begin{array}{l}\text { Details in the section 'Scattered rain events on } 27 \text { July } \\
2010^{\prime}\end{array}$ \\
\hline 28 July & 0000 to 1100 & Scattered echoes & 30 & 1.1 & Echoes scattered over the whole observation area \\
\hline 28 July & 1720 to 2359 & No data & - & 1.4 & \\
\hline 29 July & 0000 to 1820 & No data & - & 3.1 & \\
\hline 31 July & 1120 to 1430 & Localized strong echoes & 50 & 3.6 & $\begin{array}{l}\text { Strong winds with spiral motion over the observation } \\
\text { area }\end{array}$ \\
\hline 31 July & 1430 to 2359 & No data & - & 3.0 & \\
\hline 1 August & 0000 to 1220 & No data & - & 2.1 & \\
\hline 1 August & 1240 to 1430 & Localized strong echoes & 50 & 2.5 & $\begin{array}{l}\text { Strong winds with spiral motion over the observation } \\
\text { area }\end{array}$ \\
\hline 1 August & 1430 to 1920 & No data & - & 2.3 & \\
\hline 1 August & 1920 to 2300 & Localized echoes & 40 & 2.0 & $\begin{array}{l}\text { Echoes near BAKO/BAK2 stations and moving } \\
\text { westward }\end{array}$ \\
\hline 2 August & 0000 to 2359 & Localized strong echoes & 60 & 4.0 & $\begin{array}{l}\text { Details in the section 'Localized heavy rain on } \\
2 \text { August } 2010^{\prime}\end{array}$ \\
\hline 3 August & 0300 to 0910 & Scattered weak echoes & 20 & 1.8 & $\begin{array}{l}\text { Moving through the observation area from north } \\
\text { to south }\end{array}$ \\
\hline 3 August & 1220 to 1500 & Localized strong echoes & 50 & 2.6 & $\begin{array}{l}\text { Strong wind bursts with spiral motion over the } \\
\text { observation area }\end{array}$ \\
\hline 3 August & 1500 to 1605 & No data & - & 1.8 & \\
\hline 3 August & 1605 & Localized strong echoes & 50 & 1.8 & Echoes near BAKO/BAK2 stations \\
\hline 3 August & 1605 to 2210 & No data & - & 3.2 & \\
\hline 3 August & 2210 to 2359 & Localized strong echoes & 50 & 1.8 & Echoes near CJKT station \\
\hline 4 August & 0000 to 0930 & Scattered weak echoes & 20 & 2.2 & Echoes east and north of the observation area \\
\hline 4 August & 1245 to 1500 & Localized strong echoes & 50 & 2.4 & Echoes near BAKO/BAK2, PKYN, and CTGR stations \\
\hline
\end{tabular}

Timespans not reported in the table are those during which the CDR was functioning, but no echoes over the observation area were measured. max., maximum; st.dev., standard deviation. 
and $0.94 \mathrm{~mm}$, respectively. Any inter-station PWV variation exceeding $2 \mathrm{~mm}$ (i.e., twice the standard deviation) was thus considered as containing significant geophysical information, i.e., spatial fluctuations of water vapor. In the bottom panel of Figure 6, we have plotted the time variation of the standard deviation of the five PWV results. The standard deviation showed sharp peaks reaching up to 3 to $4 \mathrm{~mm}$ in the morning of 27 and 29 July and in the afternoon of 31 July and 2 to 3 August. In particular, it exceeded $3 \mathrm{~mm}$ for few hours in the afternoon of 2 August. It should be noted that the absolute PWV values estimated for each station depend on the station altitude; hence, a fraction of the inter-station standard deviation is due to the altitude difference. However, this fraction is expected to be constant over time; therefore, it does not affect the time variability of the standard deviation. In any case, it is advisable to deploy new GNSS stations (or to select stations in existing networks) at approximately the same altitude.

Table 2 shows an overview of the rain clouds detected by the CDR in Serpong. The highest values of standard deviation appear to be associated to the strongest echoes detected by the CDR over the observation area. A thorough statistical study on the relation between the characteristics of rain events and the horizontal PWV inhomogeneity in western Java is planned for our future works.

The next two subsections will focus on the precipitation events associated with two of these spatial variations: a relatively wide precipitation encompassing the Jakarta area (CJKT, CTGR, PKYN stations) on 27 July, coinciding with the local maximum of PWV in this campaign, and a localized heavy rainfall near Bogor (BAKO/BAK2 stations) on 2nd August, coinciding with the highest peak of standard deviation.

\section{Characteristics of two precipitation phenomena observed during the observation campaign \\ Scattered rain events on 27 July 2010}

The meteorological conditions during the rainfall events on 27 July were investigated by referring to satellite images on infrared and water vapor channels provided by the Japan Meteorological Agency, as well as the CDR in Serpong. The infrared satellite images indicated that convective clouds were intermittently generated in the western Pacific region around the Borneo Island; at times, these cloud systems moved southwestward from the equatorial region toward the Indian Ocean passing over the Java Island. On 26 July, the water vapor satellite images indicated moist air associated with a cloud area that approached from the Borneo Island toward the Java Island. Considerable rainfall occurred on 27 July in Jakarta and surrounding areas; the BMKG rain gauges registered 20 to $30 \mathrm{~mm}$ of 3-hourly precipitation, mostly during the morning. Convective clouds were sporadically generated around the north coast of the Java Island on that day, and the cloud system moved southwestward encountering the mountainous region south of Jakarta. Then, the convective clouds rapidly developed in a wide area that included the campaign sites. As the cloud system moved southwestward, three distinct rain events were detected by the CDR, from 0000 to 0200 LT (Figure 7, top), from 0400 to 0600 LT (Figure 7, middle), and from 0700 to 0930 LT (Figure 7, bottom) ${ }^{\mathrm{b}}$. The

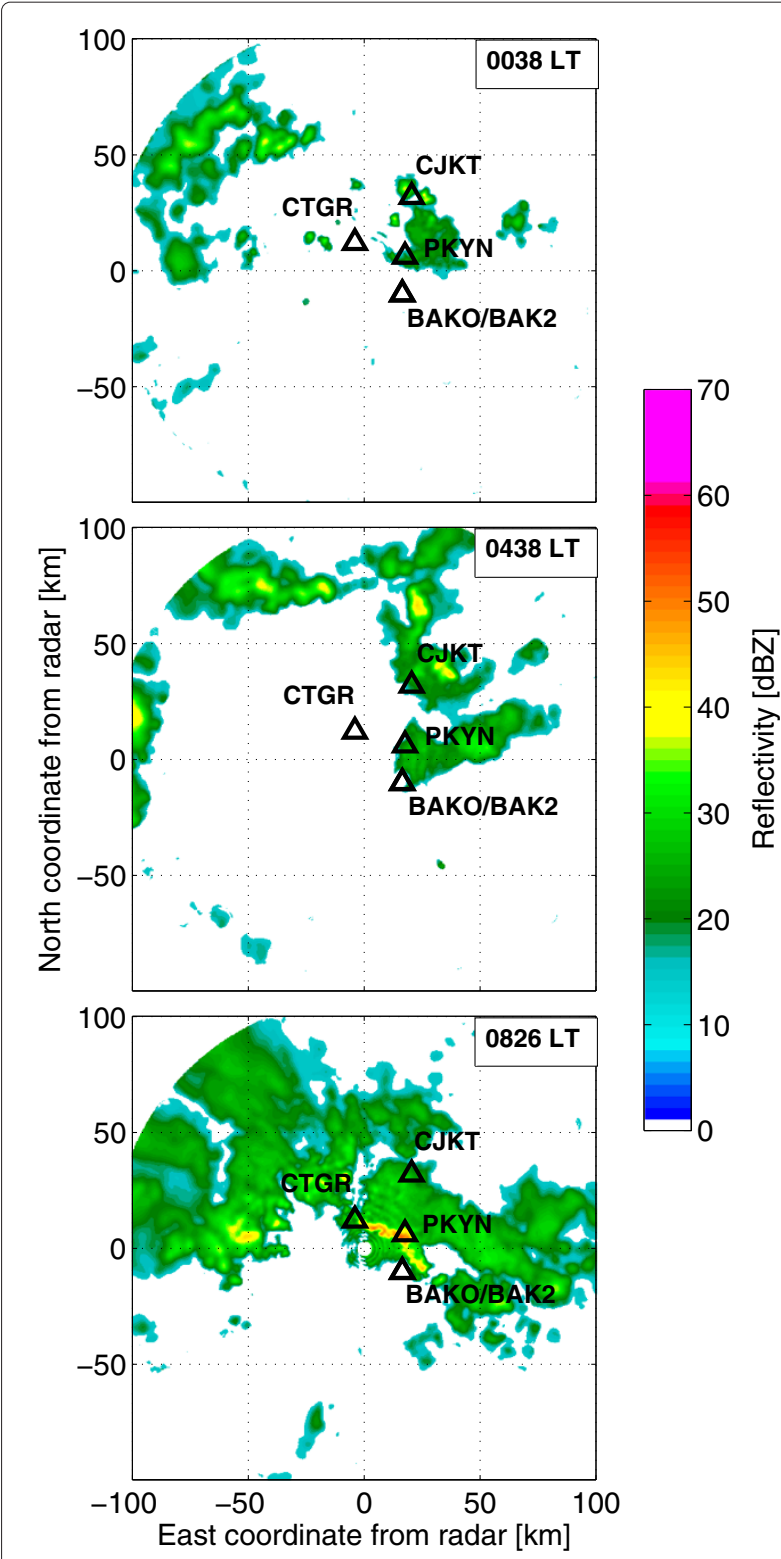

Figure 7 Radar observations on 27 July. Serpong C-band Doppler Radar reflectivity observations at $5 \mathrm{~km}$ height on 27 July 2010 at 0038 LT (top), 0438 LT (middle), and 0826 LT (bottom). 
spatial inhomogeneity of PWV detected by the GPS stations, as indicated by the inter-station standard deviation in Figure 8, also shows three distinct peaks, which correspond in time to the three rain events. During the first event (from 0000 to $0200 \mathrm{LT}$ ), the GPS-derived PWV was larger at CJKT, CTGR, and PKYN than at BAKO/BAK2, suggesting a horizontal gradient of the water vapor distribution from the north (coast) to the south (mountains) and causing the first peak in standard deviation among the GPS stations. The second event (from 0400 to 0600 LT) was similarly characterized by a north-south (coast to mountains) gradient, with significantly higher water vapor values at CJKT compared to the other stations; this station may have sensed increased amounts of water vapor coming from the ocean, which could be associated to the precipitation clouds that developed north of CJKT, as shown in the middle panel of Figure 7. The third event (from 0700 to $0930 \mathrm{LT}$ ) saw a distinct offset between the PWV estimated by CJKT and CTGR stations and that estimated by the other three stations, leading to an increment of the standard deviation lasting about $3 \mathrm{~h}$, from 0600 to 0900 LT. Toward the end of this timespan, also PKYN, BAKO, and BAK2 started registering a PWV increment, coinciding with the rain cloud expansion to cover the whole GPS network, with the consequent decrease of inter-station inhomogeneity (bottom panel of Figure 7).

\section{Localized heavy rain on 2 August 2010}

The rain event on 2 August was identified thanks to the highest peak in standard deviation shown in Figure 6. The rain gauges of the three BMKG weather stations, in fact, did not detect it since its extents were limited to a relatively small area (about $15 \times 15 \mathrm{~km}^{2}$ ) close to Bogor, where no weather station data were available. The rain event was also relatively short in time, about $2 \mathrm{~h}$, with CDR echoes appearing from 1500 to 1700 LT. Figure 9 shows the CDR reflectivity observations at three instants related to significant features of the PWV time series monitored by the GPS network, shown in Figure 10, or to significant observational evidence from the CDR: at $1228 \mathrm{LT}$, the standard deviation surpassed the threshold of $2 \mathrm{~mm}$, which in the previous example was found to anticipate the formation of rain clouds, while the CDR still did not detect strong reflectivity (Figure 9, top panel); at $1528 \mathrm{LT}$, the first radar echoes, which appeared west of BAKO/BAK2 stations at $1500 \mathrm{LT}$, reached their maximum values, about $55 \mathrm{dBZ}$ (Figure 9, middle panel); shortly after their disappearance, a second set of echoes appeared east of BAKO/BAK2 stations, with even smaller spatial extents (about $10 \times 15$ $\mathrm{km}^{2}$ ), again with maximum reflectivity values of about $55 \mathrm{dBZ}$ (Figure 9, bottom panel). Unfortunately, the CDR data are missing from 1540 to $1658 \mathrm{LT}$; thus, it is not possible to know exactly when the second set of echoes appeared. The first event seems to be associated to a
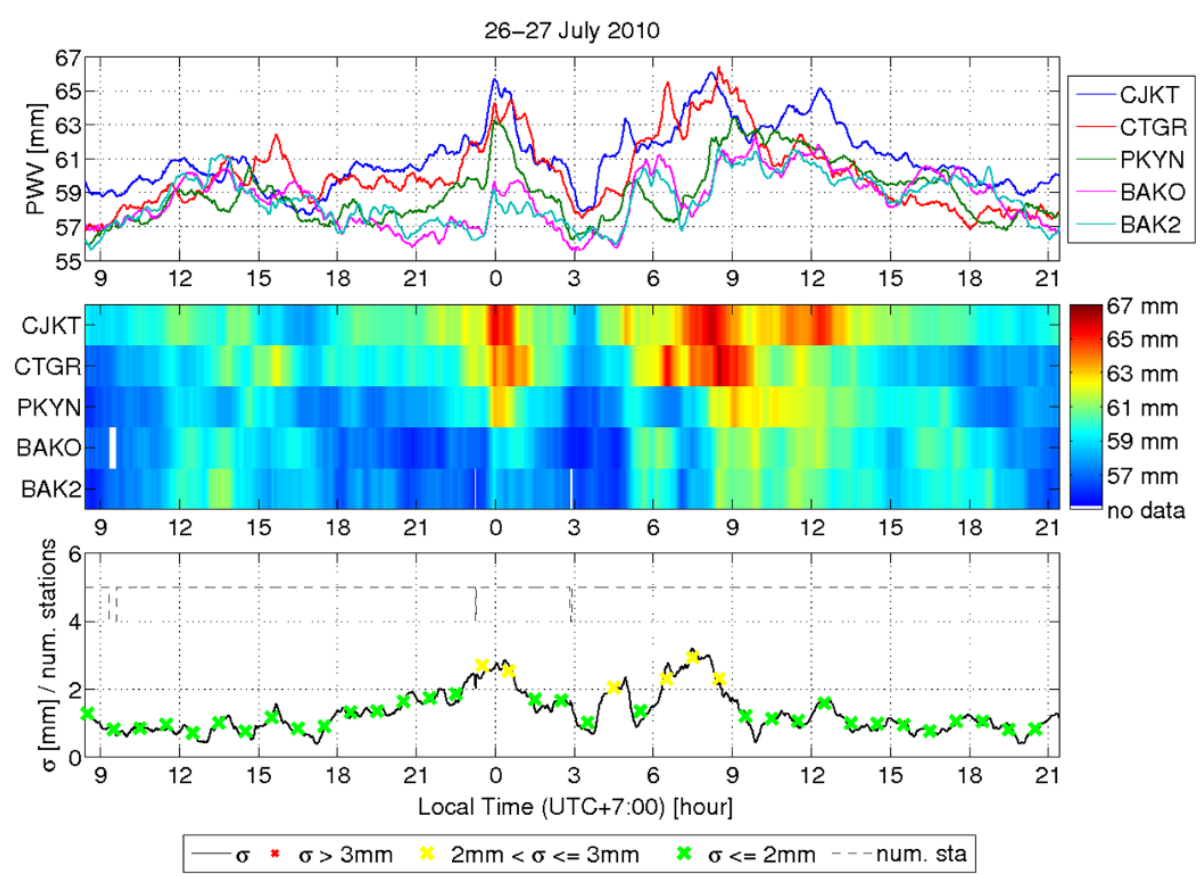

Figure 8 Spatial variations of GPS-derived PWV on 27 July. Line (top) and matrix (middle) plots of GPS-derived PWV time series 26 to 27 July 2010 (in LT); inter-station standard deviation (bottom), every $30 \mathrm{~s}$ (solid line) and hourly (crosses). The number of available stations at each epoch is overlaid on the bottom plot as a dashed line. 


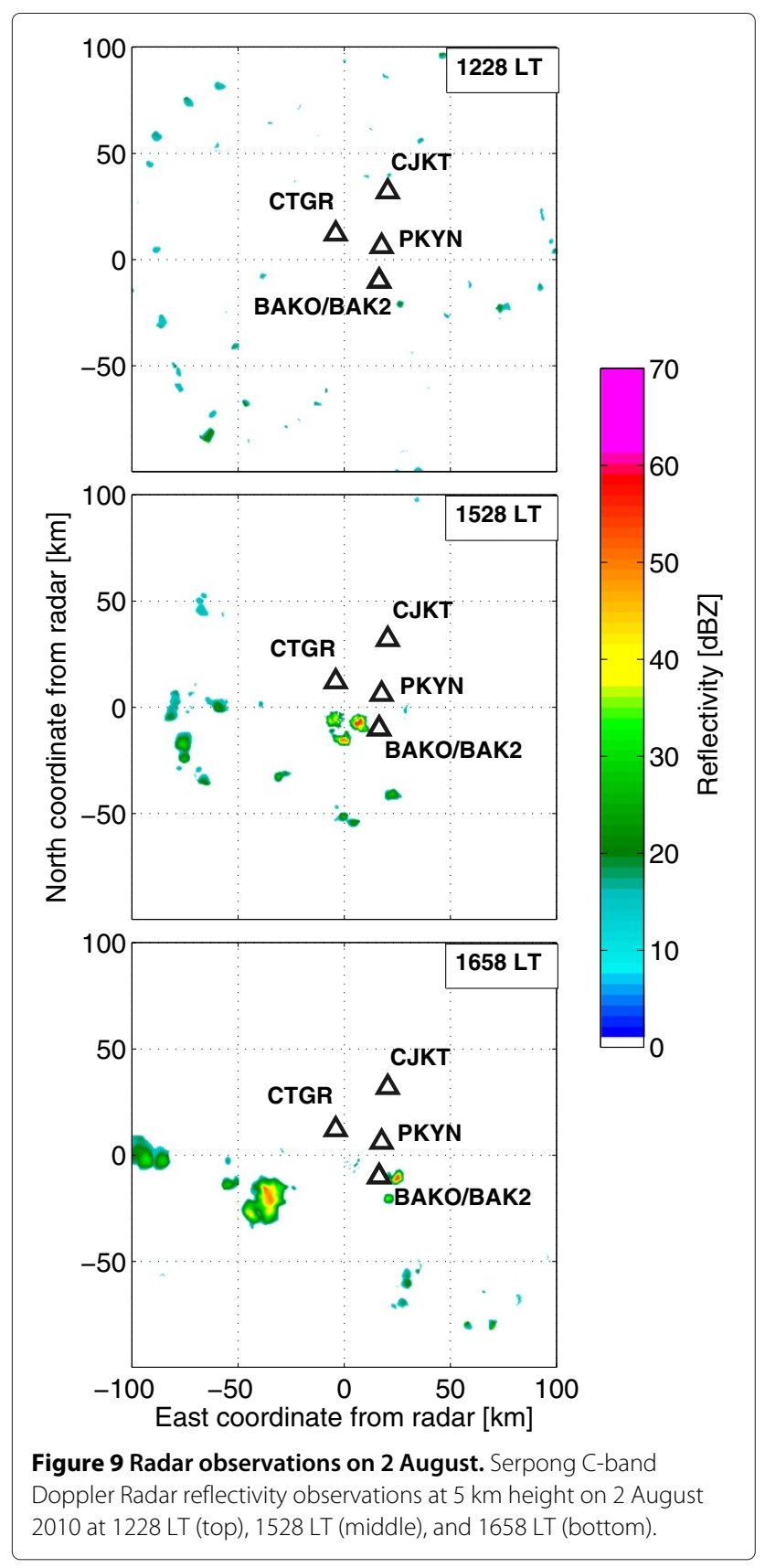

gradual increase of PWV from the coast, moving southwestward (first detected by CJKT station, then CTGR, and lastly PKYN). The second event seems to be related to a steep increase in PWV detected by both BAKO and BAK2 stations (see Figure 10).

\section{Temporal variations of GPS-derived PWV around Jakarta}

The time variability of PWV for each GPS station during the entire campaign was evaluated by means of time derivatives of PWV estimates, with a time step of $10 \mathrm{~min}$. The time step was chosen empirically, based on the magnitude of the temporal fluctuations observed in the PWV time series. The results are plotted in Figure 11, revealing the presence of several peaks of PWV time variations. The time variations were stronger during the second part of the campaign, in August, as it can partially be seen also in the top and middle panels of Figure 6. The strongest fluctuations were detected by the inland stations, while CJKT, on the coast, had generally smoother time series. The main fluctuations, in August, appeared more often in the late afternoon (1600 to $1700 \mathrm{LT})$, and preliminary comparisons with CDR observations suggest that they were consistently associated to the formation of rain clouds. Minor fluctuations appeared almost every day also during the night, within a timespan of about \pm 1 h from midnight, usually for all stations. These nocturnal fluctuations are generally not associated to clouds detected by the CDR, with some exceptions such as that between 26 and 27 July, which can be seen in the top panel of Figure 8: while in this case there was also a significant spatial variation more clearly associated to the rain clouds seen in the top panel of Figure 7, in other cases all stations exhibited temporal fluctuations of similar magnitude, the spatial variation was not significant, and rain clouds were not detected by the CDR. Further investigations on these anomalous time variations are currently ongoing.

\section{Conclusions}

A PWV observation campaign with five GPS receivers was carried out in Jakarta and Bogor, Indonesia for about ten days from 23 July to 5 August 2010. A total of 21 radiosondes was launched, with a time interval of $6 \mathrm{~h}$ from 27 July to 2 August.

The relation between the mean atmospheric temperature $\left(T_{\mathrm{m}}\right)$ and the surface temperature $\left(T_{\mathrm{s}}\right)$, which is crucial for converting the GPS wet delay to PWV, was investigated. The regression relations between $T_{\mathrm{m}}$ and $T_{\mathrm{s}}$ proposed by Bevis et al. (1992) and by Shoji (2010) were compared to temperature observations by radiosondes in order to evaluate whether they could be reliably applied for PWV retrieval in tropical regions. A temperature inversion layer frequently appeared below $300 \mathrm{~m}$ altitude at night, causing an overestimation of $T_{\mathrm{m}}$ by 2 to $4 \mathrm{~K}$, which, in turn, introduced an error in PWV of about $0.5 \mathrm{~mm}$. While this error was deemed acceptable for the purpose of our campaign, future work is required to establish an appropriate relation for the Indonesian region, by statistical analysis of routine radiosonde soundings.

Atmospheric pressure and temperature were continuously monitored only at one of the GPS stations. However, 


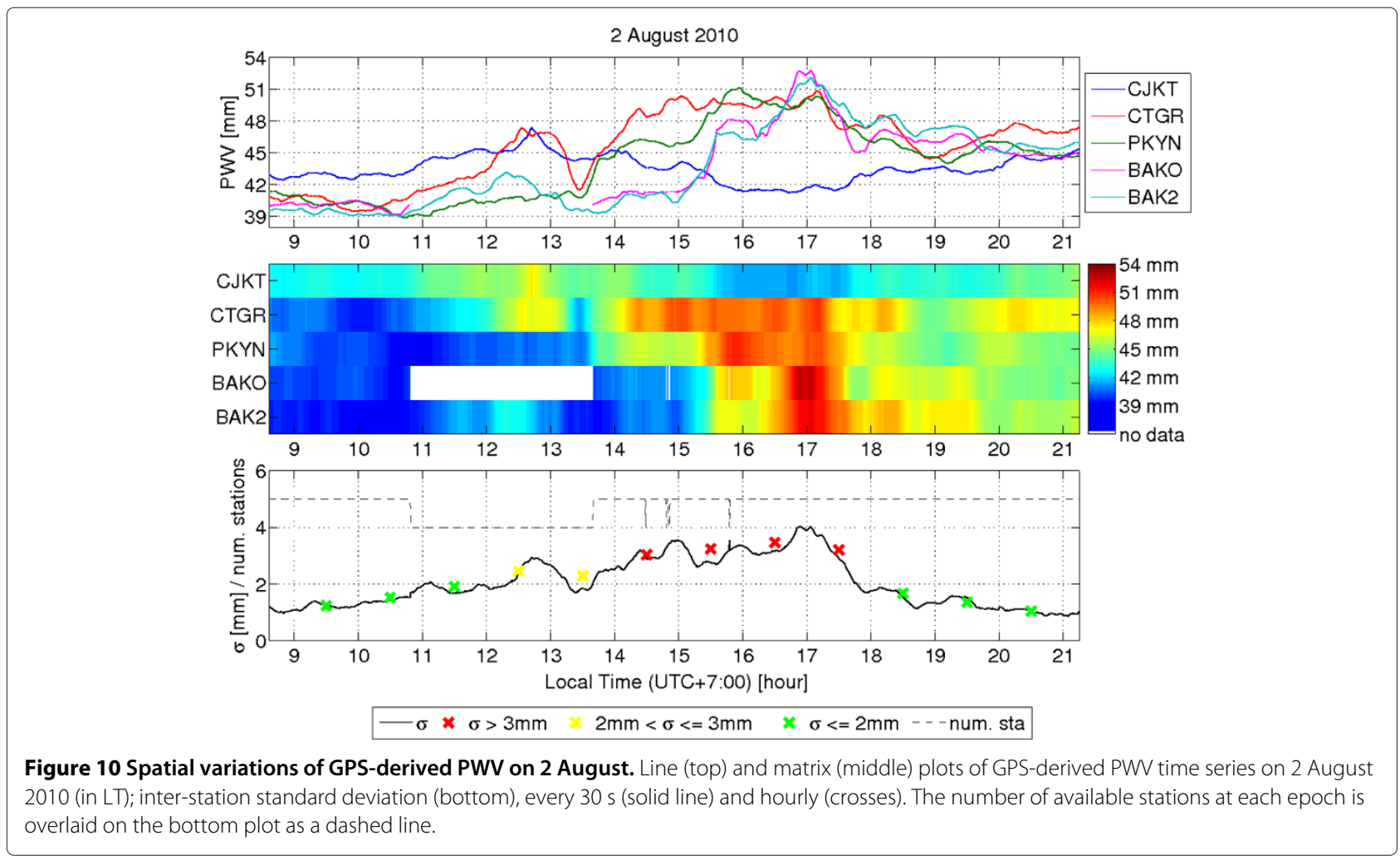

by compensating its pressure readings considering the height difference, it was possible to infer pressure time series for all the GPS stations. These inferred values were validated by comparison with 3-hourly pressure records taken at a routine weather station located in the study area, as well as an aneroid barometer and an additional pressure sensor, yielding errors lower than $1 \mathrm{hPa}$, i.e., about $0.4 \mathrm{~mm}$ in PWV. Regular semi-diurnal pressure tides with amplitudes of 3 to $5 \mathrm{hPa}$ were confirmed, corresponding to 1.1 to $1.8 \mathrm{~mm}$ in PWV. It is therefore advisable to employ ground pressure readings for PWV retrieval from GPS observations instead of relying on modeled pressure values.

C-band Doppler Radar observations and infrared satellite images indicated a passage of clouds moving southwestward from the equator toward the Indian Ocean through the Java Island during 26 to 29 July, and 3-hourly precipitation of 20 to $30 \mathrm{~mm}$ was recorded on the 27 of July by rain gauges within the observation area. An increase in GPS-derived PWV for all stations, up to about $67 \mathrm{~mm}$, coincided with this precipitation event. A second heavy rain event, characterized by significantly smaller spatial scales, was observed in the southern area of the GPS network. Spatial variations in the retrieved PWV were observed to have a strong correlation with both these events. In general, the spatial inhomogeneity of PWV started increasing before the observation of strong radar echoes within the GPS observation area, suggesting the possibility to use it as an index to predict precipitation events or at least as a parameter within a more complex index including other meteorological observations. The time variation of PWV observed by each station exhibits a correlation with the diurnal cycle of water vapor, with stronger fluctuations appearing during the late afternoon (1600 to $1700 \mathrm{LT})$, usually in conjunction with precipitation. Anomalous time fluctuations were observed during the night, within \pm 1 h from midnight, which require further investigations.

The GPS meteorology technique was proved to be useful to investigate severe weather conditions over Indonesia, complementing existing meteorological observation systems. The currently existing Indonesian network of GPS stations (IUGG 2011) could thus be useful not only for geodesy or seismology but also for meteorological research and applications. The analysis of spacetime variations of GPS-derived PWV has potential to allow the identification of precursors for nowcasting local convective rain, which might trigger hazardous events such as floods and landslides. A fundamental requirement to achieve this goal is the near real-time processing of GPS observations (i.e., by using near real-time satellite orbits and clocks), which is the target of our future works. 

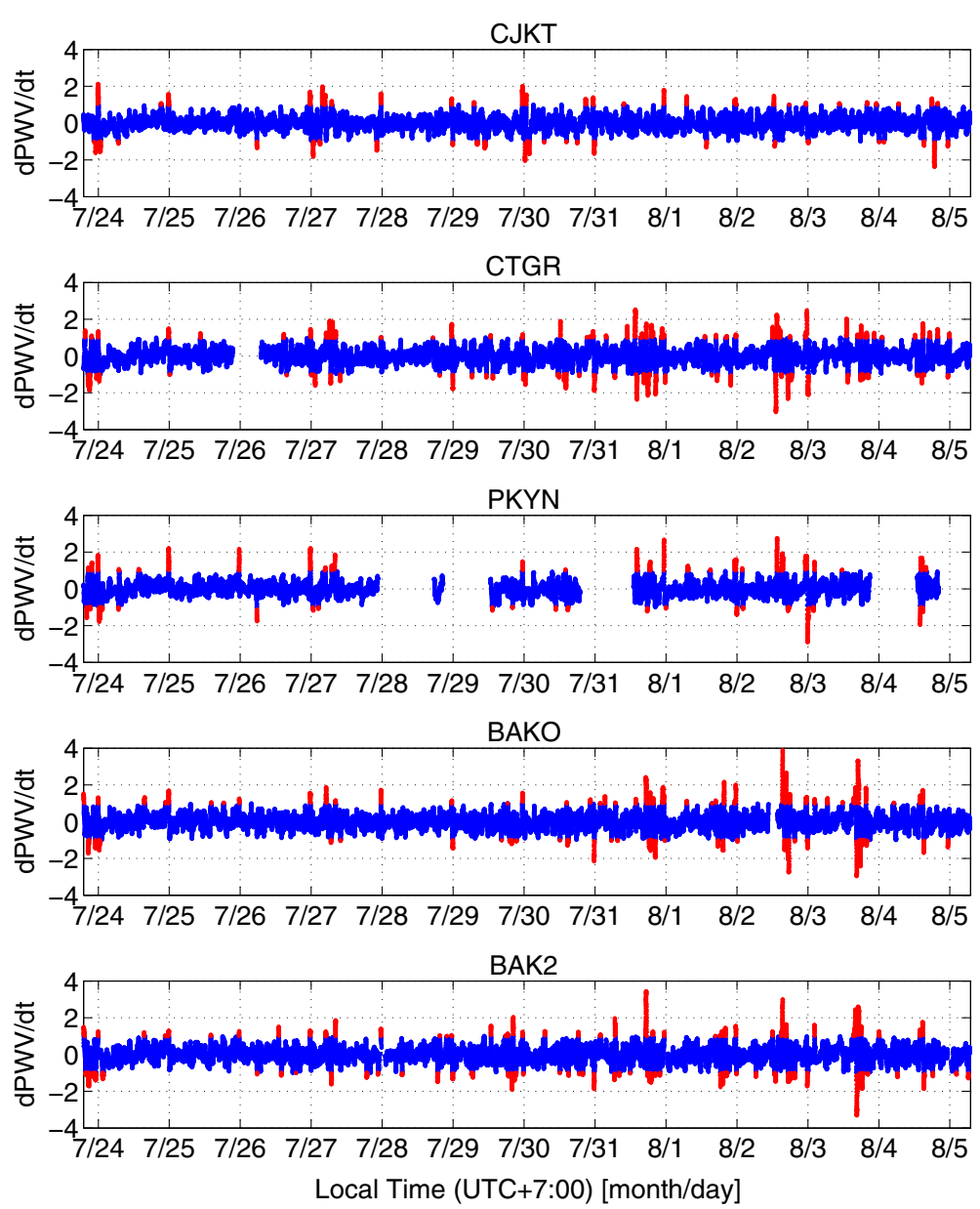

Figure 11 Time variations of GPS-derived PWV. Time derivative of PWV ( $\mathrm{dt}=10 \mathrm{~min})$; the $y$-axis represents the time variation of PWV in mm over $10 \mathrm{~min}$. The different colors represent time variations exceeding $\pm 1 \mathrm{~mm} / 10 \mathrm{~min}$ (the threshold was arbitrarily chosen to highlight the peaks).

\section{Endnotes}

ae.g., GPS stations BELF, BUCU, GARI, GRAZ, HERS, HERT, and TERS, all compared to RS92SGP soundings.

${ }^{\mathrm{b}}$ All the CDR reflectivity maps in this paper are constant altitude plan position indicator (CAPPI) plots, at $5 \mathrm{~km}$ altitude, produced by means of the open source software library Python ARM Radar Toolkit (Py-ART 2013), developed at the Atmospheric Radiation Measurement (ARM) Climate Research Facility (USA).

\section{Competing interests}

The authors declare that they have no competing interests.

\section{Authors' contributions}

ER processed the GPS observations for PWV retrieval, carried out the pressure analysis and adjustment, and participated in the the PWV space-time analyses, CDR comparisons, and manuscript draft. KS conducted the field experiments, processed the radiosonde data, analyzed the temperature profiles, studied the regression relation between $T_{\mathrm{s}}$ and $T_{\mathrm{m}}$ and participated in the manuscript draft. S provided GPS observations of the stations operated by BIG, and TM participated in the radiosonde field experiments. TT proposed and guided the research direction of this work, provided insights and interpretations related to the meteorological aspects and atmospheric physics, and reviewed the results. All authors read and approved the final manuscript.

\section{Acknowledgements}

This research was supported by the Sustainability/Survivability Science for a Resilient Society Adaptable to Extreme Weather Conditions (GCOE-ARS), which is one of the Global Center of Excellence programs at Kyoto University, under the Ministry of Education, Culture, Sports, Science and Technology of Japan (MEXT). It was also supported by the coordination funds for promoting space utilization provided by MEXT. We appreciate the devoted efforts by the staff of BIG and LAPAN for conducting the GPS and radiosonde experiments. We extend our gratitude to Dr. Hiromu Seko and Dr. Yoshinori Shoji of the Meteorological Research Institute (Japan Meteorological Agency), who gave us constructive comments and warm encouragement. We are grateful to Dr. Shuichi Mori of JAMSTEC and Dr. Fadli Syamsudin of BPPT for the support regarding the CDR raw data, which was obtained under the financial support by the Science and Technology Research Partnership for Sustainable Development (SATREPS) of the Japan Science and Technology Agency (JST) and the Japan International Cooperation Agency (JICA). Lastly, we would like to thank the members of the Py-ART mailing list for their help in improving the reflectivity plots obtained with the excellent Py-ART open source software library. 


\section{Author details}

${ }^{1}$ Research Institute for Sustainable Humanosphere (RISH), Kyoto University, Gokasho, Uji 611-0011, Japan. ${ }^{2}$ Indonesian Geospatial Information Agency (BIG), Cibinong 16911, Indonesia. ${ }^{3}$ National Institute of Aeronautics and Space (LAPAN), Bandung 40173, Indonesia. ${ }^{4}$ Present address: Geomatics Research \& Development (GReD) srl, Como, Italy. ${ }^{5}$ Present address: Satellite Navigation Office, Satellite Applications Mission Directorate I, Japan Aerospace Exploration Agency (JAXA), Tsukuba, Japan.

\section{Received: 28 February 2014 Accepted: 25 July 2014}

\section{Published: 29 August 2014}

\section{References}

Askne J, Nordius H (1987) Estimation of tropospheric delay for microwaves from surface weather data. Radio Sci 22(3):379-386

Bai Z, Feng Y (2003) GPS water vapor estimation using interpolated surface meteorological data from Australian automatic weather stations. J Global Positioning Syst 2(2):83-89

Berberan-Santos MN, Bodunov EN, Pogliani L (1997) On the barometric formula. Am J Phys 65:404

Bevis M, Businger S, Herring TA, Rocken C, Anthes RA, Ware RH (1992) GPS meteorology: remote sensing of atmospheric water vapor using the Global Positioning System. J Geophys Res Atmos (1984-2012) 97(D14):15787-15801

Böhm J, Niell A, Tregoning P, Schuh H (2006) Global Mapping Function (GMF): a new empirical mapping function based on numerical weather model data. Geophys Res Lett 33(7):07304

Covey C, Dai A, Marsh D, Lindzen RS (2011) The surface-pressure signature of atmospheric tides in modern climate models. J Atmos Sci 68(3):495-514

Davis J, Herring T, Shapiro I, Rogers A, Elgered G (1985) Geodesy by radio interferometry: effects of atmospheric modeling errors on estimates of baseline length. Radio Sci 20(6):1593-1607

Deblonde G, Macpherson S, Mireault Y, Héroux P (2005) Evaluation of GPS precipitable water over Canada and the IGS, network. J Appl Meteorol 44(1):153-166

EPN (2001) EUREF Permanent GNSS Network. http://www.epncb.oma.be/. Accessed 5 Aug 2014

Fernández L, Salio P, Natali M, Meza A (2010) Estimation of precipitable water vapour from GPS measurements in Argentina: validation and qualitative analysis of results. Adv Space Res 46(7):879-894

Fujita M, Kimura F, Yoneyama K, Yoshizaki M (2008) Verification of precipitable water vapor estimated from shipborne GPS, measurements. Geophys Res Lett 35(13):1-5

Fujita M, Yoneyama K, Mori S, Nasuno T, Satoh M (2011) Diurnal convection peaks over the eastern Indian Ocean off Sumatra during different MJO phases. J Meteorol Soc Jpn 89(0):317-330

IGS (2012) Real-Time Service. http://rts.igs.org/. Accessed 5 Aug 2014

IUGG (2011) Indonesian National Committee country report. Technical report, International Union of Geodesy and Geophysics

Li X, Dick G, Ge M, Heise S, Wickert J, Bender M (2014) Real-time GPS sensing of atmospheric water vapor: precise point positioning with orbit, clock and phase delay corrections. Geophys Res Lett 41(10):3615-3621

Lindzen RS, Chapman S (1969) Atmospheric tides. Space Sci Rev 10(1):3-188

Pavlis NK, Holmes SA, Kenyon SC, Factor JK (2012) The development and evaluation of the Earth Gravitational Model 2008, (EGM2008). J Geophys Res Solid Earth (1978-2012) 117(B4):1-38

Py-ART (2013) The Python ART Radar Toolkit. http://arm-doe.github.io/pyart/. Accessed 5 Aug 2014

Ray R (2013) Precise comparisons of bottom-pressure and altimetric ocean tides. J Geophys Res C Oceans 118(9):4570-4584

Rocken C, Mervart L, Lukes Z, Johnson J, Kanzaki M, Kakimoto H, lotake Y (2001) Testing a new network RTK software system In: Proceedings of the 17th international technical meeting of the satellite division of the institute of navigation (ION GNSS 2004), California, 21-24 Sept 2004, pp 2831-2839

Saastamoinen J (1973) Contributions to the theory of atmospheric refraction. Bull Geod (1946-1975) 107(1):13-34

Sapucci LF, Machado LA, Monico JF, Plana-Fattori A (2007) Intercomparison of integrated water vapor estimates from multisensors in the Amazonian region. J Atmos Ocean Tech 24(11):1880-1894
Sato K, Realini E, Tsuda T, Oigawa M, Iwaki Y, Shoji Y, Seko H (2013) A high-resolution, precipitable water vapor monitoring system using a dense network of GNSS receivers. J Disast Res 8(1):37-47

Shoji Y (2010) Accurate estimation of precipitable water vapor using groundbased GPS, observation network and its data assimilation into a mesoscale numerical weather prediction model. PhD thesis, Kyoto University

Vömel H, Selkirk H, Miloshevich L, Valverde-Canossa J, Valdés J, Kyrö E, Kivi R, Stolz W, Peng G, Diaz J (2007) Radiation dry bias of the Vaisala RS92 humidity sensor. J Atmos Ocean Tech 24(6):953-963

Van Baelen J, Aubagnac J-P, Dabas A (2005) Comparison of near-real time estimates of integrated water vapor derived with GPS, radiosondes, and microwave radiometer. J Atmos Ocean Tech 22(2):201-210

Wang J, Zhang L (2008) Systematic errors in global radiosonde precipitable water data from comparisons with ground-based GPS measurements. J Clim 21(10):2218-2238

Wang J, Zhang L, Dai A (2005) Global estimates of water-vapor-weighted mean temperature of the atmosphere for GPS applications. I Geophys Res Atmos (1984-2012) 110(D21):1-17

Wang J, Zhang L, Dai A, Van Hove T, Van Baelen J (2007) A near-global, 2-hourly data set of atmospheric precipitable water from ground-based GPS measurements. J Geophys Res Atmos (1984-2012) 112(D11):1-17

WMO (2008) Guide to meteorological instruments and methods of observation (WMO-No. 8) 7th edn.. World Meteorological Organization, Geneva

Wu P, Hamada J-I, Mori S, Tauhid YI, Yamanaka MD, Kimura F (2003) Diurnal variation of precipitable water over a mountainous area of Sumatra Island. J Appl Meteorol 42(8):1107-1115

Wu P, Hara M, Fudeyasu H, Yamanaka MD, Matsumoto J, Syamsudin F, Sulistyowati R, Djajadihardja YS (2007) The impact of trans-equatorial monsoon flow on the formation of repeated torrential rains over Java Island. Sci Online Lett Atmosphere 3:93-96

Wu P, Arbain AA, Mori S, Hamada J-i, Hattori M, Syamsudin F, Yamanaka MD (2013) The effects of an active phase of the Madden-Julian oscillation on the extreme precipitation event over western Java Island in January 02013. Sci Online Lett Atmosphere 9:79-83

Yamanaka MD, Hashiguchi H, Mori S, Wu P-M, Syamsudin F, Manik T, Hamada J, Yamamoto MK, Kawashima M, Fujiyoshi Y, et al. (2008) HARIMAU radar-profiler network over the Indonesian maritime continent: a GEOSS early achievement for hydrological cycle and disaster prevention. J Disaster Res 3:78-88

Yoneyama K, Fujita M, Sato N, Fujiwara M, Inai Y, Hasebe F (2008) Correction for radiation dry bias found in RS92 radiosonde data during the MISMO field experiment. Sci Online Lett Atmosphere 4:13-16

Zumberge J, Heflin M, Jefferson D, Watkins M, Webb F (1997) Precise point positioning for the efficient and robust analysis of GPS data from large networks. B3 102:5005-5017

doi:10.1186/2197-4284-1-17

Cite this article as: Realini et al: An observation campaign of precipitable water vapor with multiple GPS receivers in western Java, Indonesia. Progress in Earth and Planetary Science 2014 1:17.

\section{Submit your manuscript to a SpringerOpen ${ }^{\circ}$ journal and benefit from:}

- Convenient online submission

- Rigorous peer review

- Immediate publication on acceptance

- Open access: articles freely available online

- High visibility within the field

- Retaining the copyright to your article

Submit your next manuscript at $>$ springeropen.com 